\title{
How to Make Perpetrators in Denial Disclose More Information About Their Crimes
}

\author{
Serra Tekin \\ Pär Anders Granhag \\ Leif A. Strömwall \\ Aldert Vrij
}

Author Note

Serra Tekin, Department of Psychology, University of Gothenburg; Pär Anders

Granhag, Department of Psychology, University of Gothenburg, Norwegian Police University College, Department of Psychology, University of Oslo; Leif A. Strömwall, Department of Psychology, University of Gothenburg; Aldert Vrij, Department of Psychology, University of Portsmouth

Correspondence concerning this article should be addressed to Serra Tekin, Department of Psychology, University of Gothenburg, PO Box 500, SE 40530, Gothenburg, Sweden. Email serra.tekin@psy.gu.se 


\begin{abstract}
This study examined interview techniques for eliciting admissions from perpetrators of a crime. Two techniques derived from the Strategic Use of Evidence (SUE) framework (SUEConfrontation and SUE-Confrontation/Explain) were compared to an Early Disclosure of Evidence technique. Participants $(N=75)$ performed a mock criminal task divided into three phases before being interviewed. In the SUE conditions, statement-evidence inconsistencies were obtained by strategic interviewing for Phases 1 and 2. For both SUE conditions, the interviewer confronted the suspects with these inconsistencies, emphasizing that withholding information undermined their credibility. For the SUE-Confrontation/Explain condition, the suspects were asked to explain each inconsistency. To restore their credibility, the suspects in the SUE-conditions were expected to become more forthcoming in Phase 3 (the phase which lacked information). The suspects in the SUE-Confrontation condition (vs. the suspects in the Early Disclosure condition) disclosed more admissions about Phase 3. As predicted, the suspects in the SUE conditions perceived the interviewer to have had comparatively more information about Phase 3. The suspects in the SUE-Confrontation/Explain condition strived to maintain their credibility either by fitting their story to the evidence or by sticking to the initial story. The study shows that the SUE technique is effective for eliciting admissions.
\end{abstract} Keywords: admissions, inconsistency, strategic use of evidence, counter-interrogation strategies, denial 
How to make perpetrators in denial disclose more information about their crimes

The main goal of a suspect interview is to obtain relevant and critical information. There is an increasing interest among psycho-legal researchers to find ways to elicit information from suspects using effective and ethical techniques (e.g., Meissner, Kelly, \& Woestehoff, 2015; Tekin et al., 2015, Walsh \& Bull, 2015). The research literature shows that humane approaches (e.g., to build rapport), as opposed to oppressive approaches (e.g., to press for information), increase the likelihood of eliciting true confessions (see Meissner et al. 2014) and yield more information (e.g., Evans et al., 2013). However, the literature is scarce with respect to specific techniques that aim to elicit information from suspects. As a contribution to fill this void we examined an information gathering tactic for cases in which admissions are needed to infer guilt or innocence.

Admission elicitation can best be described as attaining crime-related information that can substantiate a suspect's guilt or innocence (e.g., Perry, 2012; Slough, 1959). For the present study, the term admission refers to information that potentially incriminates the suspect (e.g., admitting being at the crime scene), but does not involve the suspect taking responsibility for the commission of the crime (i.e., a confession). For cases in which a suspect denies the wrongdoing, and where there is little or no evidence, it is necessary to elicit information. This is a challenging task because guilty suspects typically avoid providing incriminating details (e.g., Granhag, Clemens, \& Strömwall, 2009; Strömwall \& Willen, 2011).

\section{Strategic Use of Evidence Framework}

The Strategic Use of Evidence (SUE) framework is based on a set of principles that can be used for several purposes in a suspect interview, for example to detect deception or to elicit admissions (Granhag \& Hartwig, 2015). According to this framework, a suspect's perception of the evidence will influence his or her choice of counter-interrogation strategy 
(i.e., the suspect's attempt to convince the interviewer of his or her innocence; Granhag \& Hartwig, 2008), and this strategy in turn will affect what and how much information the suspect will disclose. The perception of the evidence refers to the hypothesis the suspect forms about the interviewer's prior knowledge (Moston \& Engelberg, 2011).

Research shows that innocent and guilty suspects differ in their counter-interrogation strategies. Most innocent suspects have nothing to conceal and are therefore typically forthcoming. In contrast, guilty suspects typically refrain from revealing self-incriminating information (Hartwig, Granhag, \& Strömwall, 2007; Strömwall, Hartwig, \& Granhag, 2006). Importantly, the available evidence can be used strategically in order to magnify these verbal differences. If the interviewer asks for a free recall and exhausts the suspect's possible alternative explanations to the evidence before disclosing the evidence, it is likely that a guilty suspect will provide a statement that is inconsistent with the evidence (e.g., Hartwig, Granhag, Strömwall, \& Vrij, 2005). Differently put, if a guilty suspect perceives the interviewer not to hold a certain piece of information (e.g., 'He does not seem to know I have been to the Metro Building on Sunday evening'), s/he will then likely adopt a withholding strategy to avoid self-incrimination. Hence, the interviewer will elicit statement-evidence inconsistencies. Moreover, after the evidence is disclosed, a guilty suspect may change his or her story to adapt to the evidence (e.g., Granhag, Strömwall, Willén, \& Hartwig, 2013). Hence, the interviewer will elicit yet another cue to deceit: Within-statement inconsistencies.

So far, and as discussed above, the SUE framework has primarily been used to elicit cues to deception and truth, but it can also be used to elicit admissions from withholding suspects (Granhag \& Hartwig, 2015). Assume that a guilty suspect perceives the interviewer to hold a certain piece of information (e.g., 'He probably knows that I was in the Metro Building on Sunday evening'), s/he will then consider it fruitless to withhold or deny the information the interviewer already knows. Hence, the suspect will be forthcoming with that 
particular piece of information. The interviewer will then elicit an admission if s/he did not already possess that information.

In support of this reasoning, research has shown that suspects' perception of the evidence affects the outcome of the interview (e.g., denials or admissions): The more evidence a guilty suspect believe the interviewer to hold, the more forthcoming s/he will be in his or her attempt to avoid statement-evidence inconsistencies (Granhag et al., 2009; Luke, Dawson, Hartwig, \& Granhag, 2014; Tekin, Granhag, \& Mac Giolla, 2014).

\section{Using the SUE Framework to Elicit Admissions}

Consider a crime that is divided into three different phases, and that each phase has a different theme (e.g., meeting an accomplice, stealing a file, and gathering information in preparation for an attack). Furthermore, the interviewer has evidence pertaining to two phases of the crime (evidence that is not necessarily incriminating the suspect, but raises suspicion about the person's involvement in the crime), but lacks information about the critical third phase (e.g., the period when the crime was committed). Tekin et al. (2015) studied how to interview a suspect in such a case to elicit admissions about the phase for which the interviewer lacked information (the critical phase). This was the first study that used the SUE framework to elicit admissions. They found that suspects faced with a tactical approach derived from the SUE framework overestimated the amount of information the interviewer held about the critical phase. In addition, these suspects disclosed more admissions pertaining to their activities in the critical phase compared to the suspects in the control conditions (where the evidence was disclosed at the onset of the interview or not disclosed at all).

The interview tactic used in the study by Tekin et al. (2015) was labelled the SUEConfrontation tactic. The tactic drew on the SUE framework and aimed to alter the suspects' strategies from withholding to forthcoming. In brief, the interviewer first obtained statementevidence inconsistencies by using the available evidence in a strategic manner. Next, the 
interviewer confronted the suspects with these inconsistencies to affect their perception of the evidence. As predicted, the suspects perceived the interviewer to have had more information about the critical phase (which lacked information) than s/he actually did, and this inflated perception of the evidence resulted in a shift in the suspects' counter-interrogation strategy, from a withholding to a more forthcoming. Finally, when the interviewer turned to the critical phase, the suspects' more forthcoming strategy resulted in admissions about this phase.

\section{The Present Study}

The present study used the principles of the SUE framework as means of eliciting admissions from suspects. We aimed to mirror a situation that occurs rather frequently in real-life. That is, there is evidence pertaining to some phases of a crime (evidence that does not conclusively indicate a suspect's involvement in the crime), but less or no information about a more critical phase of the crime. In the current study, the two phases for which the interviewer had evidence were labelled Phase 1 and Phase 2, and the phase where evidence was lacking was labelled the 'critical phase' or Phase 3.

We advanced previous work on two accounts. First, for the SUE-Confrontation interview used by Tekin and colleagues (2015), after confronting the suspects with their inconsistencies, the interviewer proceeded without providing the suspects the chance to explain their inconsistencies. However, in real-life situations, an interviewer is likely to challenge a suspect's inconsistencies. Hence, for the present study we introduced a tactic, named the SUE-Confrontation/Explain, for which the interviewer asked for an explanation for each inconsistency obtained. This interview style is more ecologically valid as the suspects were given the opportunity to account for the discrepancy between their statement and the evidence (Walsh \& Bull, 2015).

We expected that in the SUE-Confrontation/Explain condition, more suspects would be motivated to become forthcoming, and consequently disclose admissions in Phase 3 . The 
rationale for this was that the suspects (unlike the suspects in the SUE-Confrontation condition) would be able to restore their credibility, which may have been undermined by the statement-evidence inconsistencies, by providing explanations for those inconsistencies. Tekin et al. (2015) reported that almost half of the suspects in the SUE-Confrontation condition withheld information pertaining to the critical phase (while the rest of the suspects volunteered information). These suspects, after being confronted with their inconsistencies resulting from their withholding strategy, might have believed to have been assessed as guilty by the interviewer and that striving to appear innocent was futile. Thus, they remained withholding. The opportunity to explain the inconsistencies was expected to remedy this as the suspects could view this as a way to restore their credibility. In other words, it was expected that in the SUE-Confrontation/Explain condition (compared to the SUEConfrontation condition) a higher number of suspects would be motivated to maintain their goal to convince the interviewer of their innocence.

Second, the current study advanced previous work by closely examining the shifts in the suspects' counter-interrogation strategies during the course of the interview. That is, we adopted and analysed both objective and subjective measures. Specifically, (a) a 'forthcomingness' score was calculated for each phase of the interview allowing comparisons between phases, and (b) the suspects were asked to report their initial counter-interrogation strategies, as well as if (and if so, how) their strategies changed throughout the interview.

In addition, given the novelty of the SUE-Confrontation tactic introduced by Tekin et al. (2015), it is of importance to try to replicate the positive effects of this tactic. To this end, we compared the SUE-Confrontation and SUE-Confrontation/Explain interviews (SUE interviews) to the Early Disclosure of Evidence interview, which is common police practice in the U.S. (e.g., Leo, 1996). 
It should be noted that the current study limited its scope to suspects who were guilty of a crime. A number of recent studies demonstrate that innocent suspects are forthcoming with critical information (Hartwig, Granhag, \& Luke, 2014) and consistent with the evidence regardless of the interviewer's tactic (e.g., Luke et al., 2014; Tekin et al., 2014). Hence, unless stated otherwise, hereafter the term 'suspect' refers to suspects who committed the criminal act.

\section{Hypotheses}

We predicted that strategic interviewing (i.e., the two types of SUE interview) would generate more statement-evidence inconsistencies in Phase 1 and Phase 2 than the Early Disclosure interview (Hypothesis 1). Furthermore, we hypothesised that the suspects interviewed with the two SUE interviews (vs. the Early Disclosure interview) would perceive the interviewer to possess more information about the critical phase (Phase 3) before being asked about this phase (Hypothesis 2). The evidence disclosure and the confrontations were identical in both SUE interviews, thus we had no reason to expect a difference between the two SUE interviews with respect to their influence on the suspects' perception of the amount of evidence the interviewer held about the critical phase.

Key to our reasoning was that the suspects in the two SUE conditions would be faced with statement-evidence inconsistencies in Phases 1 and 2 (due to having underestimated the interviewer's knowledge), and we argue that this would make them conscious about how much information the interviewer may possess about Phase 3. In other words, they would form a hypothesis about the interviewer's knowledge about Phase 3, and this hypothesis would guide their decision of how much information to provide about this particular phase of the crime. In contrast, the suspects in the Early Disclosure condition were expected to be less conscious about the interviewer's knowledge about Phase 3, and instead continue to await and react upon the interviewer's initiative with respect to the disclosure of evidence. Hence, 
for the two SUE conditions, we predicted a strong positive correspondence between the suspects' perception of the interviewer's knowledge about Phase 3 and the level of admissions, whereas we expected no such correspondence for the Early Disclosure condition (Hypothesis 3).

Based on the train of thought outlined above, we predicted that the SUEConfrontation/Explain condition would result in more admissions with respect to Phase 3, compared to the SUE-Confrontation and Early Disclosure conditions. The rationale for this was that we expected more suspects (in the SUE-Confrontation/Explain condition) to be motivated to avoid further inconsistencies in Phase 3, as a result of having had the opportunity to explain their inconsistencies in Phases 1 and 2 (Hypothesis 4a). Furthermore, we predicted that the Early Disclosure condition would result in fewer admissions than both SUE conditions (Hypothesis 4b).

Finally, we predicted that the suspects in the two SUE conditions sooner (after Phase 1) or later (after Phase 2) would switch from a withholding to a more forthcoming counterinterrogation strategy. Conversely, the suspects in the Early Disclosure condition were expected to start off as forthcoming, and then after having accounted for the evidence disclosed to them in Phase 1 and Phase 2, become more withholding in Phase 3 (Hypothesis $5)$.

\section{Method}

\section{Participants and Design}

Students and staff members $(N=78)$ from various departments at the University of Portsmouth (UK) were recruited through advertisements on several locations on the university premises. Three participants were excluded due to either interviewer error $(n=1)$ or failure to follow instructions $(n=2)$, yielding a final sample of 75 participants (40 female and 35 male; 50 students and 25 staff members). Their age ranged from 18 to 62 years $(M=$ 
27.51 years, $S D=10.75$ ). Upon arriving at the laboratory, participants were randomly assigned to one of the three interview conditions. Twenty five participants were allocated to each condition. All participants signed an informed consent form. After the experiment, they were fully debriefed and given $£ 5$ as compensation. The study lasted approximately one hour per participant. The study was approved by the Science Faculty Ethics Committee.

A between-subjects design was employed. The independent variable was interview type: SUE-Confrontation/Explain, SUE-Confrontation, and Early Disclosure. The dependent variables were; objective analyses of the suspects' verbal behaviour (statement-evidence inconsistencies, admissions, and 'forthcomingness'), and the suspects' perceptions of the evidence.

\section{Procedure}

The mock crime. Participants were told that the university officials were testing the security measures on the university premises to see whether they can detect criminal activities. They were instructed to imagine themselves as a dedicated member of a criminal group and to undertake a secret mission as part of a larger operation, which was to prepare an attack on the university premises. The mission consisted of three phases, each with a different theme. All tasks were performed individually on the university premises. Participants were provided with written instructions together with some maps of the locations they were supposed to visit.

Phase 1. In the first phase, participants received a key from an accomplice (one of the experimenters) for entering an office later on: They (1) left the Department building (King Henry Building) for a short while; (2) waited for the accomplice outside behind the building by a signpost; (3) received a key; and (4) after a brief dialogue (in which the accomplice asked if the participant knew what to do next), went back into the building. 
Phase 2. In the second phase, participants e-mailed a file from a laptop: They (1) went to the third floor of King Henry Building; (2) entered an office with the key received in Phase 1; and (3) found a laptop with a file named 'The Codes' on the desktop. This file contained scripts that were to be used in the attack. They then (4) logged on to their private e-mail accounts; and (5) e-mailed this file to another accomplice.

Phase 3. In the final phase, participants collected several documents containing important information about the attack: They (1) left the King Henry Building and went to another university building nearby, the Park Building; (2) took the lift; (3) went to the fourth floor (top floor) of the building; (4) located a cupboard behind which there was an envelope left for them; (5) went one floor down to the third floor; (6) collected a box of documents from the shelves situated in the corridor; (7) went all the way down to the basement to complete the last part of their mission, and (8) put the envelope inside the box, and placed this package in the empty space behind the lift for an accomplice to pick up later. Once the mission was complete they returned to the laboratory in King Henry Building.

The evidence. The actions described above generated evidence that cast suspicion on the participants, but did not conclusively indicate guilt of involvement in a criminal activity. Phase 1 and Phase 2 generated three pieces of evidence each. The evidence for Phase 1 included eyewitness statement indicating that the suspect; (1) had been outside behind the King Henry Building; (2) had talked to a man/woman outside (depending on the accomplice's gender); and (3) had received an object from that man/woman. The evidence for Phase 2 included; (1) an eyewitness statement indicating that the suspect had been on the third floor of King Henry Building; and (2) a report from the computer technician showing that the suspect had logged on to his or her e-mail account, which (3) also indicated that the suspect had entered a room on that same floor. 
The interviewer possessed information that a package was found behind the lift in the basement of the Park Building, and that the package contained important information about an attack on the university premises. Moreover the interviewer had access to the evidence pertaining to Phases 1 and 2. Importantly, the interviewer did not possess any evidence about Phase 3 (i.e., the critical phase). Ground truth was established for each phase to code the data for statement-evidence inconsistencies and admissions. In Phase 1, the accomplice confirmed that each participant stood by the signpost outside behind the building and talked to him or her. In Phase 2, the e-mail account was managed by the experimenter to ensure that all participants had sent the e-mail. It was necessary for participants to enter the office to be able to e-mail the file. Finally, after all tasks were performed, the experimenter went to the Park Building's basement to ensure that every document was collected and placed within the empty space behind the lift. This confirmed that it was a deliberate choice later in the interview to admit to, or conceal, the activities performed in Phase 3.

The interviews. Once participants returned to the laboratory, they received new instructions. They were informed that the university officials had found a suspicious package (without revealing where it was found) and that break-ins and thefts had been reported on campus. Therefore, an investigative team was interviewing people who had been on the premises that day, including the participants. The given instructions stated that the goal for the participants was to convince the interviewer of their innocence. Moreover, they were informed about the importance of concealing facts relating to their criminal activities. They were given 10 minutes to prepare for the interview. To increase participants' motivation, they were informed that they would be awarded $£ 5$ only if the interviewer believed them to be innocent. In fact, all participants received $£ 5$. Participants were interviewed individually according to pre-scripted protocols. The interviews were conducted by five interviewers to demonstrate that the findings were not 
dependent on an individual interviewer. Interviewers 1 and 2, both aged 27, were Ph.D. students at the University of Portsmouth. Interviewer 1 (a male) conducted 21 interviews and Interviewer 2 (a female) conducted 11 interviews. Interviewers 3, 4 and 5 were all female bachelor students at the University of Portsmouth, aged 18, 18 and 19, respectively, and the numbers of interviews they conducted were 11, 15 and 17, respectively. All interviewers received a two hour training session delivered by the first author. All interviewers conducted all three interview types and were blind to the hypotheses of the study. Interviews started with the interviewer introducing him/herself, and informing the suspects that they were under suspicion of several criminal activities. The interview protocols were divided into three phases, with each phase corresponding to the three phases of the mock crime in chronological order. The interviewer posed questions pertaining to Phases 1 and 2 and then initiated a break informing the suspects that s/he would be back in the room to ask further questions. Five minutes later, the interviewer went back into the room to pose questions pertaining to Phase 3. The suspects were unaware that Phase 3 was critical for the interviewer. The rationale behind this was that the suspects would likely be withholding if they knew what the interviewer aimed to achieve (i.e., to elicit new information pertaining to Phase 3). All interviews were audiotaped.

SUE-Confrontation/Explain interview. The structure of the interview for Phases 1 and 2 were identical and consisted of six steps for each phase; (1) a specific question about the suspects' whereabouts (e.g., 'Have you been outside behind the King Henry Building today?'); (2) an invitation for a free narrative (only if they replied 'yes' to the previous question; e.g., 'Can you tell me what you did there?'); (3) disclosure of the evidence and confrontation (see below); (4) asking for an explanation for each statement-evidence inconsistency (e.g., 'How do you explain the inconsistency between your statement and the 
evidence showing that you did talk to a man?'); (5) feedback on the suspects' explanation (see below); and (6) a five minute break.

The disclosure of the evidence and confrontation (step 3) was dependent on the suspects' denial or admission. If the suspects denied being at a certain place at step 1 (e.g., 'No, I was not outside behind the King Henry Building'), the interviewer confronted them with the three pieces of evidence pertaining to that phase. If the suspects admitted having been at a certain place, the interviewer then asked for a narrative about their activities (step 2) and confronted the suspects with the evidence in relation to what they reported in their free recall (step 3). When the suspects' statement matched the evidence, the interviewer confirmed this (e.g., 'You say that you were out behind the King Henry Building and we have eyewitness evidence showing that you were. Thus, what you say fits the evidence we have'). The interviewer confronted the suspects with each piece of evidence they omitted or contradicted and emphasised the seriousness of withholding information (e.g., 'We have eyewitness evidence indicating that you talked to a man and received something from him whilst you were outside. It is obvious that you are withholding information from me and this is serious'). After the confrontation, the interviewer required an explanation for every statement-evidence inconsistency within the suspects' statements (step 4). When the suspects provided an explanation that matched the evidence (e.g., 'Sorry, I forgot to mention that I talked to a man outside'), the interviewer confirmed this ('OK, what you say now fits the evidence we have'). In contrast, if the statement was still inconsistent with the evidence (e.g., 'You are wrong, I did not talk to a man outside'), the interviewer emphasised the seriousness of the continuing inconsistency ('What you say is still inconsistent with the evidence; this is not good for your credibility’) (step 5).

After the five minute break (step 6), the interviewer posed an open-ended question about Phase 3 ('Can you tell me what you did after you left the third floor of King Henry 
Building and before you were brought in to the interview?'). If the suspects volunteered being at specific locations (Park Building, Park Building's fourth floor, third floor and/or basement), then the interviewer asked a general question about their activities there (e.g., 'You mentioned being in Park Building's basement. Can you tell me in detail what you did there?'). If the location of the suspects' activity was ambiguous, then the interviewer asked them to clarify (e.g., 'You mentioned a cupboard. Where was this cupboard?').

As a general rule in each interview condition, the interviewer posed follow-up questions to examine whether the suspects had anything else to add to their responses (e.g., 'Is there anything else you can tell me about what you did outside behind the King Henry Building?'). Finally, the interviewer closed the interview by thanking the suspects for their cooperation. Importantly, the procedure for Phase 3 was identical across all three interview conditions. The mean duration of the SUE-Confrontation/Explain interview was 9.12 minutes $(S D=3.45)$ (the five minute break excluded).

SUE-Confrontation interview. The SUE-Confrontation interview differed from the SUE-Confrontation/Explain interview with respect to handling statement-evidence inconsistencies. Unlike in the SUE-Confrontation/Explain condition, the interviewer did not require the suspects to explain their inconsistencies. Thus, Phases 1 and 2 of the SUEConfrontation interview only involved steps 1, 2, 3, and 6 of the SUE-Confrontation/Explain interview. The questioning procedure for Phase 3 was identical to the SUEConfrontation/Explain interview. The mean duration of the SUE-Confrontation interview was 8.23 minutes $(S D=3.55)$ (the five minute break excluded).

Early disclosure interview. The Early Disclosure interview differed from the SUE interviews with respect to the timing of evidence disclosure. At the beginning of the interview, the interviewer disclosed all six pieces of evidence. The interviewer subsequently posed questions to obtain a free narrative about the suspects' activities outside behind the 
King Henry Building (Phase 1) and on the third floor of the same building (Phase 2) (e.g., 'Please tell me in detail what you did when you were outside behind the King Henry Building'). The questioning procedure for Phase 3 was identical to the SUE interviews. The mean duration of the Early Disclosure interview was 6.52 minutes $(S D=2.73)$ (the five minute break excluded).

Post interview questionnaire. Following the interview, participants were informed that the role-playing part of the experiment was now over, and that they were to fill out a post interview questionnaire in a truthful manner. First, participants reported their age, sex and occupation. Following this they reported how motivated they were to perform their tasks, and how motivated they were to convince the interviewer of their innocence (both on 7-point scales; 1 = not at all motivated, 7 = very motivated . Second, they were instructed to think back to the five minute break (i.e., right before they were asked about Phase 3). They were presented a list of eight critical details pertaining to their activities in Phase 3 (See the Codings subsection below). For each detail, they answered whether they thought the interviewer knew about that particular detail (e.g., 'Did you think the interviewer already knew you had been to the Park building?'). Finally, they answered several questions about their counter-interrogation strategies. The questions were: (1) What was your initial strategy to convince the interviewer of your innocence?; (2) Did you change your strategy at any point during the interview?; (3) If yes, when did you change your strategy?; and (4) What was your new strategy?

Codings. In order to measure statement-evidence inconsistency, we analysed the statements with regard to the number of inconsistencies in Phases 1 and 2. As mentioned, the interviewer held six pieces of evidence for Phases 1 and 2, three pieces for each phase. Thus, the number of statement-evidence inconsistencies could vary between 0 and 3 for each phase, where 3 indicated that the suspect was inconsistent with all three pieces of evidence 
pertaining to that particular phase. Both contradictions (statements that conflicted the evidence) and omissions (statements that left out the evidence) were counted as inconsistencies. A random $30 \%$ of the interviews were independently rated by two coders with respect to the number of statement-evidence inconsistencies for Phases 1 and 2. Intraclass correlation coefficients (ICC) were calculated, showing excellent agreement across all phases; .88, 95\% CI $[.71, .95]$ for Phase $1 ; .96,95 \%$ CI $[.91, .99]$ for Phase 2 . The disagreements were settled in a discussion between the coders. One of the coders subsequently coded the remaining interviews.

As mentioned earlier, in the post interview questionnaire, the participants were asked for each of the eight critical details - whether they thought the interviewer possessed that piece of information prior to being asked about Phase 3. The perception of the evidence was calculated by counting the number of details the participants perceived the interviewer to possess. Hence, the perception score ranged from 0 to $8(0=$ the interviewer knew nothing, and $8=$ the interviewer knew everything).

To measure admissions, we analysed the statements for the critical phase only (i.e., Phase 3). The critical admissions pertained to (1) being inside Park Building; (2) taking the lift; (3) being on the fourth floor; (4) mentioning the cupboard on the fourth floor; (5) being on the third floor; (6) mentioning the shelves on the third floor; (7) being in the basement; and (8) being in the empty space behind the lift in the basement. Each admission was counted as 1 . Hence, the total admission score for a suspect ranged from 0 to $8^{1}$. A random $30 \%$ of the interviews were independently rated by two coders with respect to admissions. Excellent agreement was obtained for the admission scores, ICC $=.98,95 \%$ CI $[.96, .99]$. The few disagreements were settled in a discussion between the coders. One of the coders subsequently coded the remaining interviews.

\footnotetext{
${ }^{1}$ Assigning the same value to each admission might be viewed as a limitation considering that the admissions may weigh differently in real-life (i.e., some may be more incriminating than the others). However, studying the weight of the admissions is beyond the scope of the present study.
} 
Suspects' level of 'forthcomingness' was measured by calculating a ratio for their consistency. The aim of this transformation was to have comparable scores in each phase. In doing so, we calculated the ratio of the number of statement-evidence consistencies to the total number of pieces of evidence for Phases 1 and 2 separately. For instance, if a suspect was consistent with one piece of evidence out of three, the forthcomingness score would be .33. Similarly, we calculated the ratio of the number of admissions in the suspects' statements to the total number of possible critical admissions for Phase 3. For instance, if a suspect admitted to four details out of eight, the forthcomingness score would be .50 .

Finally, to trace the direction of the shifts in suspects' counter-interrogation strategies, two coders independently coded a random $30 \%$ of suspects' self-reported initial and new counter-interrogation strategies as forthcoming or withholding. Strategies were categorised as forthcoming, for instance, when suspects reported to have stayed close to the truth or admitted to details without revealing criminal intent. The category of withholding strategies consisted of suspects reporting to have denied everything or answered to a bare minimum. Some strategies reported by the suspects were not verbal (e.g., 'I stayed calm'); thus they were categorized as other. Interrater agreement was $88.6 \%$ (Cohen's $\mathrm{K}=.70)$ for the suspects' self-reported strategies. One of the coders categorised the remaining material.

\section{Results}

\section{Preliminary Analyses}

The suspects in the three conditions did not differ in their motivation to perform the mock crime, $F(2,72)=1.02, p=.36, r=.17,95 \% \mathrm{CI}[-.06, .38]$, or in their motivation to convince the interviewer of their innocence, $F(2,72)=3.07, p=.053, r=.28,95 \%$ CI $[.06$, $.48]$. The mean scores were well above the midpoint of the scales $(M=6.28, S D=0.86$ and $M=6.19, S D=0.88$, respectively). We further tested for interviewer effects, but found no statistical indication of any interviewer eliciting different outcomes than the other 
interviewers. This was tested with Interviewer $\times$ Condition interactions for each dependent variable, all $p$-values $>.09$.

\section{Hypotheses-Testing Analyses}

Statement-evidence inconsistency. We predicted that the two types of SUE interviews would result in more statement-evidence inconsistencies than the Early Disclosure interview. A mixed-design ANOVA was conducted with Interview Condition (two SUE conditions combined vs. Early Disclosure) as the between-subjects factor and Phase as the withinsubjects factor. There was a main effect for Interview Condition, $F(1,73)=54.30, p<.001, r$ $=.65,95 \%$ CI $[.50, .76]$. As predicted, the SUE conditions resulted in more statementevidence inconsistencies $(M=1.71, S D=0.11)$ compared to the Early Disclosure condition $(M=0.30, S D=0.16)$. There was no significant main effect of Phase, $F(1,73)=1.28, p=$ $.26, r=.13,95 \%$ CI $[-.10, .35]$. Importantly, there was a significant interaction effect between Interview Condition and Phase, $F(1,73)=4.72, p=.03, r=.25,95 \%$ CI $[.02, .45]$. Simple effects tests at each phase (Phases 1 and 2) showed that the two SUE conditions combined ( $M$ $=1.90, S D=0.84)$ produced more statement-evidence inconsistencies than the Early

Disclosure condition $(M=0.24, S D=0.72)$ both at Phase $1, F(1,73)=71.24, p<.001, r=$ $.70,95 \%$ CI $[.56, .80]$ and at Phase $2, F(1,73)=22.05, p<.001, r=.48,95 \%$ CI $[.28, .64]$ (two SUE conditions combined, $M=1.52, S D=1.01$; Early Disclosure condition, $M=0.36$, $S D=0.99)$. Hence, Hypothesis 1 was supported.

We expected no difference between the two SUE conditions with respect to statementevidence inconsistencies. However, a mixed-design ANOVA with Interview Condition (SUE-Confrontation/Explain vs. SUE-Confrontation) as the between-subjects factor and Phase as the within-subjects factor revealed a significant main effect of Interview Condition, $F(1,48)=4.32, p=.04, r=.29,95 \%$ CI $[.01, .53]$. Unexpectedly the suspects in the SUEConfrontation/Explain condition were overall more inconsistent with the evidence $(M=1.94$, 
$S D=0.16)$ than the suspects in the SUE-Confrontation condition $(M=1.48, S D=0.16)$.

There was a main effect of Phase demonstrating that Phase 1 resulted in more statementevidence inconsistencies than Phase 2, $F(1,48)=8.40, p=.006, r=.39,95 \%$ CI $[.13, .60]$. No interaction effect was found, $F(1,48)=.58, p=.45, r=.11,95 \% \mathrm{CI}[-.17, .38]$. Of special interest was the change over the phases within each SUE condition. Thus, we conducted multivariate simple effects tests for each SUE condition, comparing the change in inconsistency scores from Phase 1 to Phase 2. Suspects in the SUE-Confrontation condition were more inconsistent with the evidence in Phase 1 than in Phase $2, F(1,48)=6.70, p=.01$, $r=.35,95 \%$ CI $[.08, .57]$. No such difference occurred for the SUE-Confrontation/Explain condition, $F(1,48)=2.78, p=.14, r=.23,95 \%$ CI $[-.05, .48]$. See Table 1 for the descriptive statistics.

\section{Table 1 about here}

Suspects' perception of the evidence. Suspects in the two SUE conditions were expected to perceive the interviewer to have had more information regarding the critical phase than the suspects in the Early Disclosure condition. A one-way ANOVA with Interview Condition (SUE-Confrontation vs. SUE-Confrontation/Explain vs. Early Disclosure) as the factor revealed a significant effect on the suspects' perception of the evidence, $F(2,72)=3.64, p=.03, r=.30,95 \%$ CI $[.08, .49]$. Planned contrasts showed that, as predicted, suspects in the SUE conditions $(M=4.62, S D=2.64)$ believed the interviewer to have had significantly more information about the critical phase than the suspects in the Early Disclosure condition $(M=3.08, S D=2.31), t(72)=-2.48, p=.02, r=.28,95 \% \mathrm{CI}$ $[.06, .48]$. Moreover, as predicted, no difference was found between the SUE conditions, $t(72)=1.06, p=.29, r=.12,95 \%$ CI $[-.11, .34]$. Hence, Hypothesis 2 was supported. See Table 1 for descriptive statistics. 
The suspects' perception of how much information they thought the interviewer had about Phase 3 was positively and significantly correlated with the amount of critical information they revealed when asked about this phase for both the SUEConfrontation/Explain condition $(p=.02, r=.48,95 \%$ CI $[.10, .74])$ and the SUEConfrontation condition $(p<.001, r=.74,95 \%$ CI $[.49, .88])$, but not for the Early Disclosure condition $(p=.24, r=.24,95 \%$ CI $[-.17, .58])$. Hypothesis 3 was supported.

Admissions. We hypothesised that the SUE-Confrontation/Explain condition would result in the highest number of admissions, whereas the Early Disclosure condition would yield the lowest number. A one-way ANOVA with Interview Condition (SUE-Confrontation vs. SUE-Confrontation/Explain vs. Early Disclosure) as the factor revealed a significant effect on admissions, $F(2,72)=6.18, p=.003, r=.38,95 \% \mathrm{CI}[.17, .56]$. Post hoc comparisons using a Bonferroni test showed that the SUE-Confrontation/Explain condition did not differ from the SUE-Confrontation condition $(p=.48)$, or from the Early Disclosure condition $(p=.13)$. Importantly, the SUE-Confrontation interview elicited more admissions than the Early Disclosure interview $(p=.002)$. See Table 1 for the descriptive statistics. In sum, Hypothesis 4a received no support; Hypothesis 4b received partial support.

We ran further analyses to clarify the results. Within the SUE-Confrontation/Explain condition, a relatively large portion of suspects $\left(n=16^{2}\right)$ provided an explanation to one or more of their inconsistencies in Phase 1 or Phase 2, whereas a smaller group of suspects $(n=$ $7^{3}$ ) did not explain any of their inconsistencies. We used an independent-sample $t$-test to compare these two subsets of suspects with respect to their admissions for Phase 3 , as examining this could shed further light on the suspects' behaviour. Suspects who accounted

\footnotetext{
${ }^{2}$ Suspects who provided explanations varied in their behaviour with respect to the percentages of inconsistencies they explained. More specifically, as many as 11 out of 16, offered an explanation to 58\% of their inconsistencies in Phase 1 and then to $100 \%$ in Phase 2. Five out of 16 explained $60 \%$ of their inconsistencies in Phase 1; however, only $20 \%$ in Phase 2 . Both groups obtained a similar admissions score $(M$ $=4.18, S D=1.66$, and $M=4.80, S D=2.17$, respectively).

${ }^{3}$ The total number of suspects does not add up to 25 as two suspects were consistent with all six pieces of evidence.
} 
for some or all inconsistencies admitted significantly more self-incriminating information about the critical phase $(M=4.38, S D=1.78)$ than suspects who did not explain any of their inconsistencies $(M=1.43, S D=1.62), t(21)=-3.74, p=.001, r=.75,95 \%$ CI $[.50, .89]$. In sum, suspects in the SUE-Confrontation/Explain condition varied in their verbal behaviour as a function of whether or not they explained their inconsistencies. This may account for the finding that this condition resulted in fewer admissions than expected.

Suspects' shifts of counter-interrogation strategies. To examine the shifts in suspects' counter-interrogation strategies, we ran separate polynomial trend analyses for each condition with respect to the suspects' 'forthcomingness' for all three phases. There was no significant trend in the SUE-Confrontation/Explain condition, $F(1,23)=3.31, p=.08, r=$ $.35,95 \%$ CI $[-.05, .65]$. However, we found an increasing linear trend over the phases for the SUE-Confrontation condition, $F(1,23)=4.45, p=.046, r=.40,95 \%$ CI $[.006, .687]$. That is, the suspects' forthcomingness gradually increased throughout the interview. A decreasing linear trend, $(F(1,23)=93.89, p<.001, r=.90,95 \% \mathrm{CI}[.78, .96])$ as well as a quadratic trend $(F(1,23)=19.10, p<.001, r=.67,95 \%$ CI $[.37, .84])$ emerged in the Early Disclosure condition. This indicated that suspects in the Early Disclosure condition had a similar level of 'forthcomingness' in Phases 1 and 2, but that their 'forthcomingness' decreased rather dramatically for Phase 3 (see Figure 1). Hypothesis 5 was partially supported.

Figure 1 about here

Suspects' self-reports on their strategy shifts. The suspects were asked whether they changed their strategies at any point during the interview. In the SUE-Confrontation condition, $68 \%(n=17)$ of suspects reported to have done so, compared to $52 \%(n=13)$ in the SUE-Confrontation/Explain condition, and 40\% $(n=10)$ in the Early Disclosure condition. The percentage of suspects who switched their strategies did not differ by 
interview type, $\chi^{2}(2, N=75)=3.96, p=.14$. The majority of the suspects reported to have changed their strategy during the five minute break (SUE-Confrontation, $n=11$; SUE-

Confrontation/Explain, $n=7$; Early Disclosure, $n=9$ ); the timing of the change did not differ by interview type, $\chi^{2}(2, N=75)=3.47, p=.18$. Furthermore, to examine the direction of the shifts, we compared suspects' self-reported initial strategies to their claimed new strategies. In the SUE-Confrontation condition, 93.75\% (15 out of 16) and in the SUEConfrontation/Explain condition, $90 \%$ of the suspects (9 out of 10) either remained forthcoming or changed their strategies from withholding to forthcoming. The corresponding percentage for the Early Disclosure condition was only $44.50 \%$ (4 out of 9$)^{4}$. See Table 2 for the direction of the shifts.

\section{Table 2 about here}

\section{Discussion}

For the present study we used strategic interviewing to inflate the suspects' perception of the interviewer's knowledge, and the inflated perceptions worked as a vehicle for eliciting admissions. In line with the principles underlying the SUE framework, and with the findings of Tekin et al. (2015), the suspects' perception of the evidence in the two SUE conditions (they overestimated the amount of evidence) affected their choice of strategy (they became more forthcoming), which in turn affected their verbal responses (they admitted to comparatively more critical information).

Furthermore, the present study advanced previous research in a number of ways. First, we examined a more ecologically valid interview tactic (SUE-Confrontation/Explain), for which the interviewer challenged the suspects' statement-evidence inconsistencies (e.g., Walsh \& Bull, 2015). We used objective measures as well as subjective measures (i.e.,

\footnotetext{
${ }^{4}$ The numbers do not add up to the total number of suspects who reported to have changed their strategies. This is because some of the suspects' responses fell into the 'other' category and were excluded.
} 
suspects' self-reports) to study the shifts in suspects' counter-interrogation strategies. In addition, compared to previous research, we used a more sensitive measure to map the suspects' perception of the evidence.

\section{Statement-Evidence Inconsistency}

As predicted, the suspects in the two SUE conditions were more inconsistent with the evidence than the suspects in the Early Disclosure condition. Moreover, in the two SUE conditions the suspects' inconsistency declined from Phase 1 to Phase 2 . This is perfectly in line with the findings reported by Tekin et al. (2015). A reasonable explanation for this is that some suspects already realised after Phase 1 that their withholding strategy did not pay off; thus they changed to a more forthcoming strategy after Phase 1 rather than after Phase 2.

Surprisingly, the suspects in the SUE-Confrontation/Explain condition were more inconsistent with the evidence than the suspects in the SUE-Confrontation condition. We argue that this was due to some suspects deciding to stay withholding throughout the SUEConfrontation/Explain interview. We will elaborate on this below.

\section{Suspects' Perception of the Evidence}

For the two SUE conditions (unlike for the Early Disclosure condition), the amount of information the suspects believed the interviewer to possess about the critical phase correlated strongly with how much information they admitted about this phase of the crime. Reasonably, the suspects thought that the statement-evidence inconsistencies undermined their credibility; thus they strived to restore their credibility. In doing so, they acted on their perception of how much information they thought the interviewer held about Phase 3. In the Early Disclosure condition, however, due to how the evidence was disclosed (i.e., early in both Phase 1 and Phase 2), the suspects awaited the interviewer to present his or her evidence about Phase 3 before revealing any information. Since the interviewer did not disclose any evidence pertaining to this phase, the suspects withheld information. Put differently, their 
perception of how much the interviewer might know regarding Phase 3 did not affect how much they disclosed about this phase.

\section{Admissions}

The SUE-Confrontation interview resulted in more admissions than the Early Disclosure interview. This finding echoes past results showing that suspects are likely to adjust their counter-interrogation strategies from less to more forthcoming to account for the amount of evidence they believe the interviewer to possess (Granhag et al., 2009; Luke et al., 2014; Tekin et al., 2015). Broadly speaking, the suspects' goal is to convince the interviewer of their innocence (Granhag \& Hartwig, 2008; Granhag, Hartwig, Mac Giolla, \& Clemens, 2015). In the SUE-Confrontation condition, the suspects who realised that the interviewer may know more than they initially thought, and that contradicting the evidence posed a threat to their perceived credibility, revised their initial withholding strategies. Hence, these suspects switched to a more goal-congruent strategy (a more forthcoming strategy) to avoid further inconsistencies, and as a result of this they volunteered more information (admissions). These findings could also be explained through a social cognitive framework, namely the self-regulation theory (Carver \& Scheier, 2012). According to this theory, people regulate their behaviour to achieve their goals. In doing so, they analyse the situation by gathering information from external sources and then deciding on the most goal-congruent strategy for that particular situation. If the strategy fails to meet the goal, they revise their hypothesis about the situation and change their strategy to attain the goal (MacKenzie, Mezo, \& Francis, 2012). In the current context, the suspects regulated their counter-interrogation strategies to attain the goal of convincing the interviewer that they were innocent.

One unexpected finding was that the SUE-Confrontation/Explain interview did not outperform the other interviews in eliciting admissions. We based our prediction on the assumption that the suspects would take the opportunity to explain their inconsistencies in an 
attempt to restore their credibility, and in fact many of them did. These particular suspects aimed to avoid further inconsistencies in Phase 3 by revealing admissions. However, a portion of the suspects in this condition were withholding throughout the interview; they refrained from explaining their inconsistencies, and they revealed fewer admissions in Phase 3 (than the suspects who explained their inconsistencies). It is possible that these suspects refrained from explaining their inconsistencies because they thought that changing their initial statement was relatively more threatening to their perceived credibility (Hartwig et al., 2014). Here it should be acknowledged that the interviewer emphasised that the unaccounted inconsistencies hampered their credibility. This might have resulted in suspects believing to have failed to provide a credible impression. As a result, they might have given up trying to convince the interviewer of their innocence, and therefore decided to stay with their withholding strategies. We argue that suspects' belief that they can restore their undermined credibility play an important role in making suspects more forthcoming during an interview.

Furthermore, suspects in the SUE-Confrontation/Explain condition who explained their inconsistencies ended up as forthcoming with respect to their activities in Phase 3 (their mean admission scores were almost as high as the suspects' in the SUE-Confrontation condition). However, the reasons why they switched to a more forthcoming strategy varied. The suspects acted in a rather similar manner with respect to their verbal behaviour in Phase 1 (i.e., they explained about $60 \%$ of their inconsistencies), but differed with respect to how they handled their inconsistencies in Phase 2: They explained either all (100\%) or some (on average 20\%) of their inconsistencies. We argue that they strived to appear credible either by fitting their story to the evidence or by maintaining within-statement consistency (by sticking to the initial story). The former group seemed to have focused on the rewarding aspect of clarifying their contradictions, while the latter group prioritised to avoid within-statement inconsistencies (see Heydon, 2004). 
We have too few data points to statistically explore the SUE-Confrontation/Explain interview further. We believe it would be worthwhile to study this interview type in future research and expand our understanding of how suspects reason during strategic interviews.

\section{Shifts in Suspects' Counter-Interrogation Strategies}

Previous research has reported contradictory findings with regard to the shifts in suspects' strategies during the course of an interview. Some researchers have found that a suspect's initial strategy is unlikely to change (Alison, Alison, Noone, Elntib, \& Christiansen, 2013; Deslauriers-Varin, Beauregard, \& Wong, 2011; Soukara, Bull, Vrij, Turner, \& Cherryman, 2009), which was true for a minority of the suspects in the present study. Some studies, however, have demonstrated that suspects may switch from a denial to a confession (or to admissions) as a result of the interviewer's strategy (e.g., Tekin et al., 2015). In the present study, the majority of the suspects who were interviewed strategically changed their counter-interrogation strategies. Critically, the suspects' strategies shifted in the expected direction; from withholding to forthcoming in the SUE conditions, and from forthcoming to withholding in the Early Disclosure condition. Importantly, the suspects' self-reports complemented these findings, speaking to the internal consistency of our findings.

Another potentially important finding is that many suspects (all conditions combined) reported to have altered their verbal behaviour during the five minute break. The break might have provided the suspects time to consider the payoff of pursuing or changing their counterinterrogation strategy. We would like to acknowledge that the basis for this finding is the suspects' self-reports, which might not be the optimal way to study this issue. Nevertheless, we believe that this finding deserves attention in future research.

\section{Practical Implications}

The current study has several practical implications. Walsh and Bull (2015) examined (among other things) how different evidence disclosure models moderate the outcome of real- 
life suspect interviews. Relating the present paper to the study by Walsh and Bull helps to illuminate the many related, yet different, research questions that need to be addressed within this emerging field. Walsh and Bull showed that gradual and late disclosure models resulted in more comprehensive accounts than an early disclosure model. The extent to which these 'comprehensive accounts' covered different themes of a crime - other than the themes for which the inconsistencies were obtained - is not clear from their analysis. For the present study, we showed that strategic disclosure models (based on the SUE framework) resulted in an increased level of admissions on the critical phase for which the interviewer held no previous information. Critically, the results of these two studies converge, although the outcome was measured in different ways. More specifically, Walsh and Bull used a rather general measure (the outcome of the full interview), whereas the present study used a more specific measure (what the suspects told on one particular and critical phase). In brief, both archival studies (like the one by Walsh and Bull), and laboratory based studies (like the present) are needed to advance our knowledge on the different effects following different ways of playing the evidence in suspect interviews.

Second, our set up was structurally similar to a situation which occurs rather frequently in real-life investigations: To have some background information about a suspect's whereabouts, but to have less or no information about a more critical phase of the crime. Our results offer an ethical approach for how to interview suspects in such cases. The tactical approach examined in the present study differs markedly from approaches that use deceit to attain confessions or admissions, e.g., by confronting the suspect with false evidence. Such trickery has been found to result in suspects admitting to crimes they have not committed (e.g., Kassin \& Gudjonsson, 2004). Importantly, the SUE framework offers interviewers a strategic and ethically defensible way to utilize already known information to obtain previously unknown information. Finally, the SUE interviews accomplished multiple goals; 
they yielded cues to deceit (i.e., statement-evidence and within-statement inconsistencies), as well as admissions. Both these outcomes are critical when a prosecutor builds a case regarding a suspect's possible involvement in a crime.

\section{Limitations}

The first limitation is that our sample consisted of students and staff members who may not be representative of the typical suspect. However, suspects in real-life situations who aim to convince the interviewer of their innocence will presumably be more motivated to employ the most goal-congruent counter-interrogation strategy. In such cases, the SUE tactics may be even more effective than in laboratory settings.

Second, we did not examine the content of the suspects' explanations which may be critical to an investigation. For instance, a thorough explanation, as opposed to a superficial one, might contain a new lead. A measure which aims to capture the content of the suspects' explanations would be beneficial in further improving the SUE interview. Moreover, interviewers in real-life cases (unlike the interviewers in the present study) may vary in their responses when suspects do or do not provide an explanation for an inconsistency. These responses may, in the next instance, affect the suspects' choice of counter-interrogation strategies, and we believe this is an important area for future research. Third, we did not require the suspects to report reasons for why they changed or did not change their strategies during the interview. The answers to such questions might have advanced our understanding of the suspects' decisions further. Fourth, the suspects were faced with the task of trying to remember how much information they estimated the interviewer to have held about the critical phase, as well as which strategies they have employed. It is possible that their retrospective self-reports were influenced by the interviewer's questions about the critical phase. On the other hand, such limitations should apply to all conditions and therefore cannot 
account for the differences found between the SUE interviews and the Early Disclosure interview. However, we encourage future research to address this critical issue.

Regarding the SUE interview itself, the technique is limited to cases in which the interviewer possesses some potentially incriminating information about the suspects' activities; therefore the findings cannot be generalised to every case. Furthermore, confronting the suspects with unverified information might have undesired outcomes, such as false admissions and/or false confessions (Meissner et al., 2014). Hence, it is essential to ensure the accuracy of the information before utilising it to influence suspects' perception of the evidence.

\section{Conclusions}

In the current study, we were able to show that the suspects' perception of the evidence, which is open to influence, moderated the counter-interrogation strategy, which in return affected the suspects' decision to conceal or reveal information (Granhag \& Hartwig, 2015). In addition, we examined a version of the SUE-Confrontation interview, which better reflected real-life situations, by allowing the suspects to explain their inconsistencies. The findings provided insight to various ways in which suspects applied their strategies to appear credible. We believe that understanding suspects' behaviour is key to counteract their strategies. In sum, the present study shows that the SUE tactics are promising for the elicitation of admissions from perpetrators. 


\section{References}

Alison, L. J., Alison, E., Noone, G., Elntib, S., \& Christiansen, P. (2013). Why tough tactics fail and rapport gets results: Observing Rapport-Based Interpersonal Techniques (ORBIT) to generate useful information from terrorists. Psychology, Public Policy, and Law, 19, 411-431. doi: 10.1037/a0034564

Carver, C. S., \& Scheier, M. F. (2012). A model of behavioral self-regulation. In P. M. Van Lange, A. W. Kruglanski, E. Higgins (Eds.), Handbook of theories of social psychology (Vol 1) (pp. 505-525). Thousand Oaks, CA: Sage Ltd.

Deslauriers-Varin, N., Beauregard, E., \& Wong, J. (2011). Changing their mind about confessing to police: The role of contextual factors in crime confession. Police Quarterly, 14, 5-24. doi: 10.1177/1098611110392721

Evans, J. R., Meissner, C. A., Ross, A. B., Houston, K. A., Russano, M. B., \& Horgan, A. J., (2013). Obtaining guilty knowledge in human intelligence interrogations:

Comparing accusatorial and information-gathering approaches with a novel experimental paradigm. Journal of Applied Research in Memory and Cognition, 2, 83-88. doi: 10.1016/j.jarmac.2013.03.002

Granhag, P. A., Clemens, F., \& Strömwall, L. A. (2009). The usual and the unusual suspects: Level of suspicion and counter-interrogation tactics. Journal of Investigative Psychology and Offender Profiling, 6, 129-137. doi: 10.1002/jip.101

Granhag, P. A., \& Hartwig, M. (2008). A new theoretical perspective on deception detection: On the psychology of instrumental mind-reading. Psychology, Crime \& Law, 14, 189200. doi: $10.1080 / 10683160701645181$

Granhag, P. A., \& Hartwig, M. (2015). The Strategic Use of Evidence (SUE) technique: 
A conceptual overview. In P. A. Granhag, A. Vrij, \& B. Verschuere (Eds.), Deception detection: Current challenges and cognitive approaches (pp. 231-251). Chichester, UK: Wiley.

Granhag, P. A., Hartwig, M., Mac Giolla, E., \& Clemens, F. (2015). Suspects' verbal counterinterrogation strategies: Towards an integrative model. In P. A. Granhag, A. Vrij, \& B. Verschuere (Eds). Deception detection: New challenges and cognitive approaches (pp. 293-314). Chichester, UK: Wiley.

Granhag, P. A., Strömwall, L. A., Willén, R. M., \& Hartwig, M. (2013). Eliciting cues to deception by tactical disclosure of evidence: The first test of the Evidence Framing Matrix. Legal and Criminological Psychology, 18, 341-355. doi: 10.1111/j.20448333.2012.02047.x

Hartwig, M., Granhag, P. A., \& Luke, T. J. (2014). Strategic Use of Evidence during investigative interviews: The state of the science. In D. C. Raskin, C. R. Honts, \& J. C. Kircher (Eds.), Credibility assessment: Scientific research an applications (pp. 1-36). Oxford, UK: Academic Press.

Hartwig, M., Granhag, P. A., \& Strömwall, L. A. (2007). Guilty and innocent suspects' strategies during police interrogations. Psychology, Crime \& Law, 13, 213-227. doi: $10.1080 / 10683160600750264$

Hartwig, M., Granhag, P. A., Strömwall, L. A., \& Vrij, A. (2005). Detecting deception via strategic disclosure of evidence. Law and Human Behavior, 29, 469-484. doi: 10.1007/s10979-005-5521-X

Heydon, G. (2004). Establishing the structure of police evidentiary interview with suspects. International Journal of Speech, Language, \& the Law, 11, 27-49. doi: 10.1558/s1l.2004.11.1.27

Kassin, S. M., \& Gudjonsson, G. H. (2004). The psychology of confessions: A review of the 
literature and issues. Psychological Science in the Public Interest, 5, 33-67. doi: 10.1111/j.1529-1006.2004.00016.x

Leo, R. A. (1996). Inside the interrogation room. The Journal of Criminal Law \& Criminology, 86, 266-303. doi: 10.2307/1144028

Luke, T. J., Dawson, E., Hartwig, M., \& Granhag, P. A. (2014). How awareness of possible evidence induces forthcoming counter-interrogation strategies. Applied Cognitive Psychology, 28, 876-882. doi: 10.1002/acp.3019

MacKenzie, M. B., Mezo, P. G., \& Francis, S. E. (2012). A conceptual framework for understanding self-regulation in adults. New Ideas in Psychology, 30, 155-165. doi: 10.1016/j.newideapsych.2011.07.001

Meissner, C. A., Kelly, C. E., \& Woestehoff, S. A. (2015). Improving the effectiveness of suspect interrogations. Annual Review of Law and Social Sciences, 11, 211-233. doi: 10.1146/annurev-lawsocsci-120814-121657

Meissner, C. A., Redlich, A. D., Michael, S. W., Evans, J. R., Camilletti, C. R., Bhatt, S., \& Brandon, S. (2014). Accusatorial and information-gathering interrogation methods and their effects on true and false confessions: A meta-analytic review. Journal of Experimental Criminology, 10, 459-486. doi: 10.1007/s11292-014-9207-6

Moston, S., \& Engelberg, T. (2011). The effects of evidence on the outcome of interviews with criminal suspects. Police Practice and Research: An International Journal, 12, 518-526. doi: 10.1080/15614263.2011.563963

Perry, C. (2012). Admissions and confessions. The Journal of Philosophy, Science \& Law, 12, 1-12. Retrieved from http://jpsl.org/archives/admissions-and-confessions/

Slough, M. C. (1959). Confessions and admissions. Fordham Law Review, 28, 96-114. Retrieved from http://ir.lawnet.fordham.edu/cgi/viewcontent.cgi?article=1622\&context=flr 
Soukara, S., Bull, R., Vrij, A., Turner, M., \& Cherryman, J. (2009). What really happens in police interviews with suspects? Tactics and confessions. Psychology, Crime \& Law, 15, 493-506. doi: 10.1080/10683160802201827

Strömwall, L. A., Hartwig, M., \& Granhag, P. A. (2006). To act truthfully: Nonverbal behaviour and strategies during a police interrogation. Psychology, Crime \& Law, 12, 207-219. doi: 10.1080/10683160512331331328

Strömwall, L. A., \& Willen, R. M. (2011). Inside criminal minds: Offenders' strategies when lying. Journal of Investigative Psychology and Offender Profiling, 8, 271-281. doi: 10.1002/jip.148

Tekin, S., Granhag, P. A., \& Mac Giolla, E. (2014, June). Strategic interviewing to elicit new information: Making liars more forthcoming. Paper presented at the annual conference of the European Association of Psychology and Law, Saint Petersburg, Russia.

Tekin, S., Granhag, P. A., Strömwall, L. A., Mac Giolla, E., Vrij, A., \& Hartwig, M. (2015). Interviewing strategically to elicit admissions from guilty suspects. Law and Human Behavior, 39, 244-252. doi: 10.1037/lhb0000131

Walsh, D., \& Bull, R. (2015). Interviewing suspects: Examining the association between skills, questioning, evidence disclosure, and interview outcomes. Psychology, Crime \& Law, 21, 661-680. doi: 10.1080/1068316X.2015.1028544 
Table 1

Descriptive Statistics on the Dependent Variables Broken Down by Interview Type and Phase

\begin{tabular}{|c|c|c|c|c|c|c|c|}
\hline Interview type & $\begin{array}{c}\text { Phase } 1 \\
\text { inc. } \\
M \\
(S D)\end{array}$ & $\begin{array}{c}\text { Phase } 2 \\
\text { inc. } \\
M \\
(S D)\end{array}$ & $\begin{array}{c}\text { Perception } \\
\text { of } \\
\text { evidence } \\
M \\
(S D)\end{array}$ & $\begin{array}{c}\text { Admission } \\
\text { score } \\
M \\
(S D)\end{array}$ & $\begin{array}{c}\text { Phase } 1 \\
\text { forth. } \\
M \\
(S D)\end{array}$ & $\begin{array}{c}\text { Phase } 2 \\
\text { forth. } \\
M \\
(S D)\end{array}$ & $\begin{array}{c}\text { Phase } 3 \\
\text { forth. } \\
M \\
(S D)\end{array}$ \\
\hline $\begin{array}{l}\text { SUE- } \\
\text { Confrontation/ } \\
\text { Explain }\end{array}$ & $\begin{array}{c}2.08 \\
(0.86)\end{array}$ & $\begin{array}{l}1.80 \\
(0.91)\end{array}$ & $\begin{array}{c}4.24 \\
(2.57)\end{array}$ & $\begin{array}{c}3.68 \\
(2.29)\end{array}$ & $\begin{array}{c}0.31 \\
(0.29)\end{array}$ & $\begin{array}{c}0.40 \\
(0.30)\end{array}$ & $\begin{array}{c}0.44 \\
(0.30)\end{array}$ \\
\hline $\begin{array}{l}\text { SUE- } \\
\text { Confrontation }\end{array}$ & $\begin{array}{c}1.72 \\
(0.79)\end{array}$ & $\begin{array}{c}1.24 \\
(1.05)\end{array}$ & $\begin{array}{c}5.00 \\
(2.71)\end{array}$ & $\begin{array}{c}4.64 \\
(2.53)\end{array}$ & $\begin{array}{c}0.43 \\
(0.26)\end{array}$ & $\begin{array}{c}0.59 \\
(0.35)\end{array}$ & $\begin{array}{c}0.57 \\
(0.33)\end{array}$ \\
\hline $\begin{array}{l}\text { Early } \\
\text { Disclosure }\end{array}$ & $\begin{array}{c}0.24 \\
(0.72)\end{array}$ & $\begin{array}{c}0.36 \\
(0.99)\end{array}$ & $\begin{array}{c}3.08 \\
(2.31)\end{array}$ & $\begin{array}{c}2.28 \\
(2.34)\end{array}$ & $\begin{array}{c}0.92 \\
(0.24)\end{array}$ & $\begin{array}{c}0.88 \\
(0.33)\end{array}$ & $\begin{array}{c}0.28 \\
(0.29)\end{array}$ \\
\hline
\end{tabular}

Note. inc. = inconsistency scores; forth. = 'forthcomingness' scores. 
Table 2

Direction of Suspects' Shifts in Their Counter-interrogation Strategies

\begin{tabular}{lccc}
\hline & \multicolumn{3}{c}{ Interview type } \\
\cline { 2 - 4 } & $\begin{array}{c}\text { SUE-Confrontation/ } \\
\text { Explain }\end{array}(\%)$ & SUE-Confrontation & Early Disclosure \\
Forth. to with. & $0(0 \%)$ & $1(6.25 \%)$ & $n(\%)$ \\
With. to forth. & $5(50 \%)$ & $5(31.25 \%)$ & $2(44.5 \%)$ \\
Remained forth. & $4(40 \%)$ & $10(62.5 \%)$ & $2(22.2 \%)$ \\
Remained with. & $1(10 \%)$ & $0(0 \%)$ & $1(11.1 \%)$ \\
\hline
\end{tabular}

Note. Forth. = forthcoming; With. = withholding. 


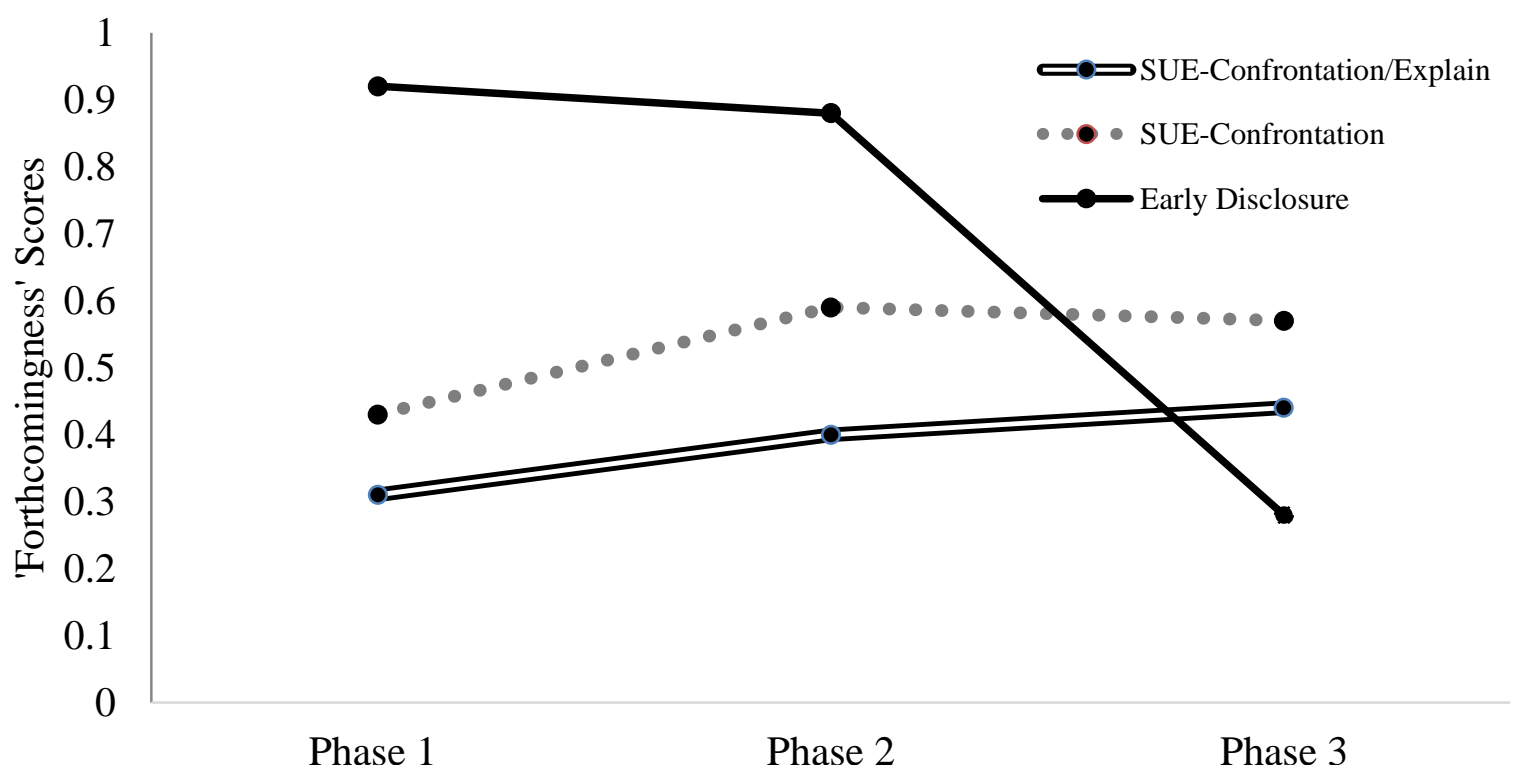

Figure 1. Suspects' 'forthcomingness' scores for each condition by Phase. 